\title{
Improving the efficiency of well workover solutions for the elimination of behind-the- casing flows
}

\author{
L.G. Rakhmaev ${ }^{1,}$ V.D. Odayev ${ }^{2}$ \\ ${ }^{I}$ Expert at the Center for Technological Development, PAO Tatneft, Russia \\ ${ }^{2}$ Technician at the Center for Technological Development, PAO Tatneft, Russia
}

\begin{abstract}
The article deals with the increase of profitability of water shutoff treatment (WST), which is used to eliminate behind-the-casing flows (cross-flow) in production and injection wells. It is presented that modern technologies of water shut-off works have low efficiency (success rate), especially in liquidation of nonperforating interval. Inefficient (wasteful) injection is currently one of the main problems in the development of oil and gas fields, as it significantly reduces the oil recovery factor in addition to the huge costs for oil companies for injection (operating costs). The article presents the results of hydrodynamic research and proposes methods for determining the presence of behind-the-casing flows (BCF) and methods for detecting wasteful injection without geophysical well-logging (a non-standard approach). The article also presents equipment for the elimination of the behind-the-casing flow and technology of its implementation.
\end{abstract}

\section{INTRODUCTION}

An alternative view on the unproductive (wasteful) injection is a behind-the-casing flow (BCF). Oil and gas companies annually spend huge amounts of money to eliminate them, but the success rate of these works does not exceed $40 \%$ (Figure 1 ).

The results of early studies $[1,2,3]$ revealed the existence of effective technologies for solving this problem. However, the applicability of these results and products is limited by their cost and conditions of use, as only the payback of the proposed technologies requires an increase of oil production no less than 250 tons/day from each well, while in the conditions that are investigated in this work, the maximum level of oil production that the company produces from one well is no more than 5-6 tons/day.

The main reasons for the low success rate of these works are:

- lack of efficient BCFE technology;

- unreasonable costs for BCFE work over, since geophysical well logging methods for determination of BCF are not sufficiently informative (Figure 2).

The main tasks solved in this study are the analysis of optimal conditions that ensure maximum efficiency of behind-the-casing flow elimination (BCFE), as well as searching for ways to reduce the operational cost of it.. Based on the obtained results, the authors developed optimal criteria for selecting objects and effective BCFE method that is applicable both at the field studied in this paper and other similar oil and gas fields. The 
fact that many other fields are confined to the field in the paper allows us to apply the results of this study at these other fields as well.

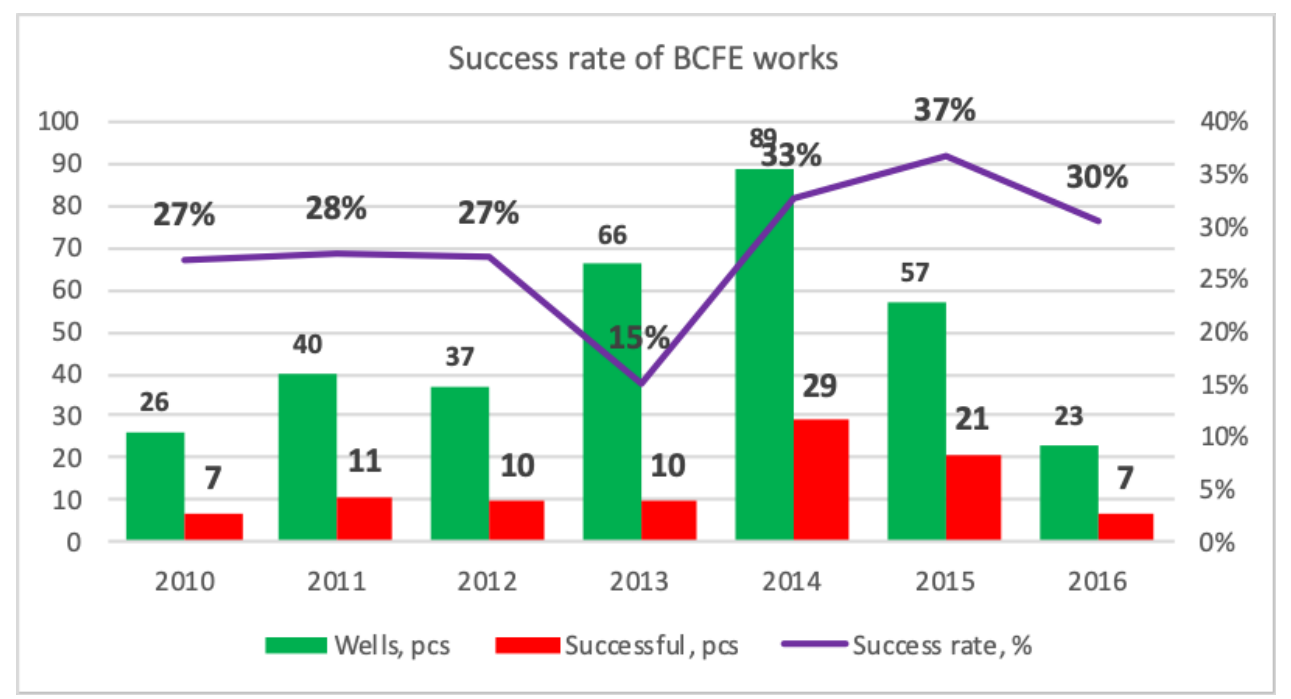

Fig. 1. Territorial Analysis of the success rate BCFE works from 2010 to 2016 at Aznakaevskneft OGPD, PAO Tatneft [5].

\section{METHODOLOGY}

For the detection of BCF, usually, a complex geophysical well logging is performed, which includes a high-precision thermal log and spectral noise logging. Figure 2 shows fragments from geophysical logging diagrams: downhole temperature (DT), indication downhole flow meter (IDF), gamma ray logs (GRL), casing collar locator (CCL), and the spectral noise logging (SNL) in the well 16748. According to the conclusion of the geophysical logging based on these DT, IDF, GRL, CCL methods, it is impossible to be sure of the presence of $\mathrm{BCF}$, but the interpretation of the spectral noise log indicates the presence of BCF below and above (up to the current depth). However, by comparing the spectrum of noises, it is difficult to estimate the filtration intensity, both in the reservoir and in the borehole annulus, since the intensity of noise (hence the flow) in the annular space is negligible. 


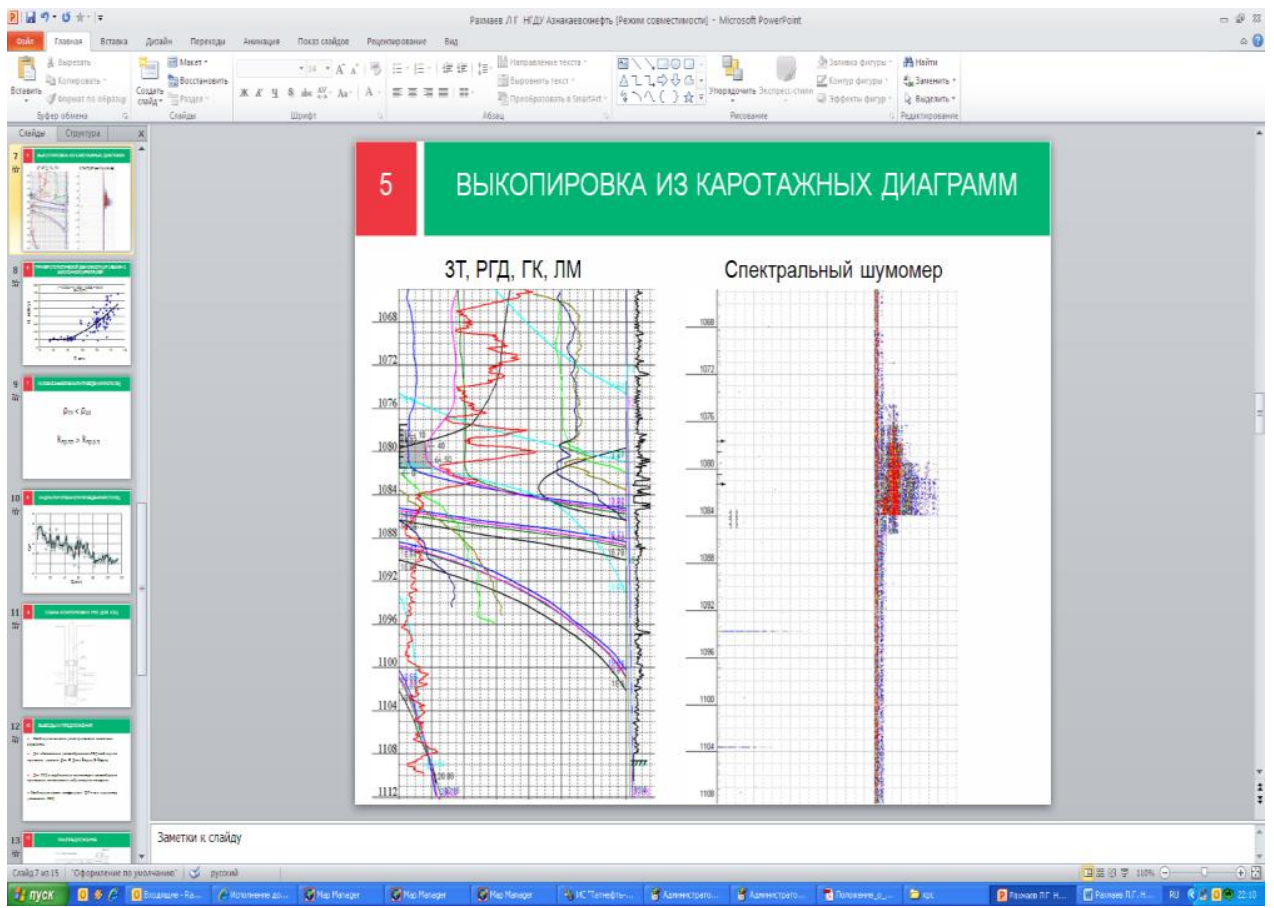

Fig. 2. Fragments from geophysical logging diagrams in the well 16748 (JSC Tatneft 1998). DT downhole temperature, IDF - indication downhole flow meter, GRL - gamma-ray logs, CCL - casing collar locator.

In addition, when geophysical well logging is complicated by the absence of a drill sump or due to the ambiguousness of logging conclusions, hydrodynamic survey using the "Mineyev method" in problem injection wells are proposed as an alternative. This method is commonly used to evaluate the permeability and injectivity of the reservoir in the near and far areas to identify the bottomhole formation zone with skin effect [4].

Successful BCF elimination technology should restore the effect of injection on nearby producing wells and restore the reservoir capacity coefficient $\mathrm{Q} / \mathrm{P}=\mathrm{f}(\mathrm{t})$, the dynamics of which can be used to assess the quality of BCFE performance. Figure 3 shows the trend of the above-mentioned coefficient after BCFE in the conditional time interval, which can serve as an additional indicator of WST success (Patent 2549639 RU MPE E 21 B 43/20). 


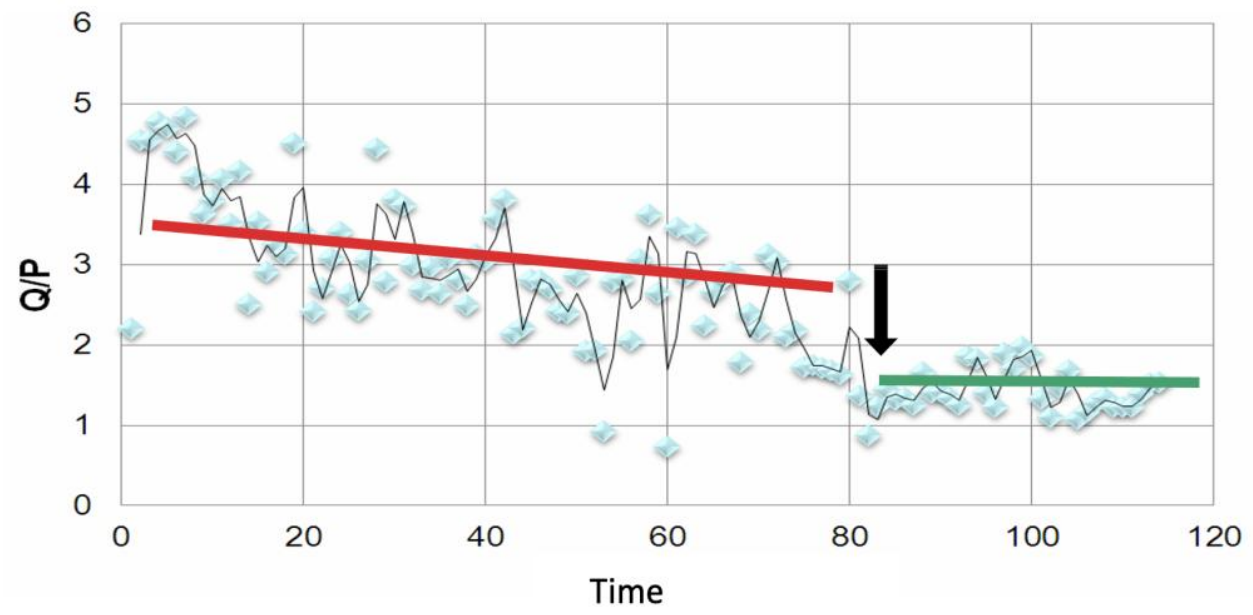

Fig. 3. Indicator of BCFE work over success time spent for BCFE (WST).

It was supposed that the presence of BCF in an injection well can be calculated by the difference between previous and current permeability and capacity in the near (i.e. annular space) and remote (i.e. formation) zones of the injection area. At the same time, it was assumed that hydraulic fracturing technology may cause BCF due to the destruction of cement sheath which leads to increasing permeability and injectivity in the near zones rather than in remote zones.

To check this assumption, well testing using the Mineyev method was performed in 13 injection wells with hydraulic fracturing. The results of data processing showed that in three wells, manely, \# 9921, 24802, and 28664, the near-zone permeability significantly exceeded its values determined before hydraulic fracturing (Table 1). The study of the dynamics based on the injectivity in the well 9972, where the value of the permeability in the remote zone was significantly higher than in the near zone, showed its gradual stabilization (Fig. 4).

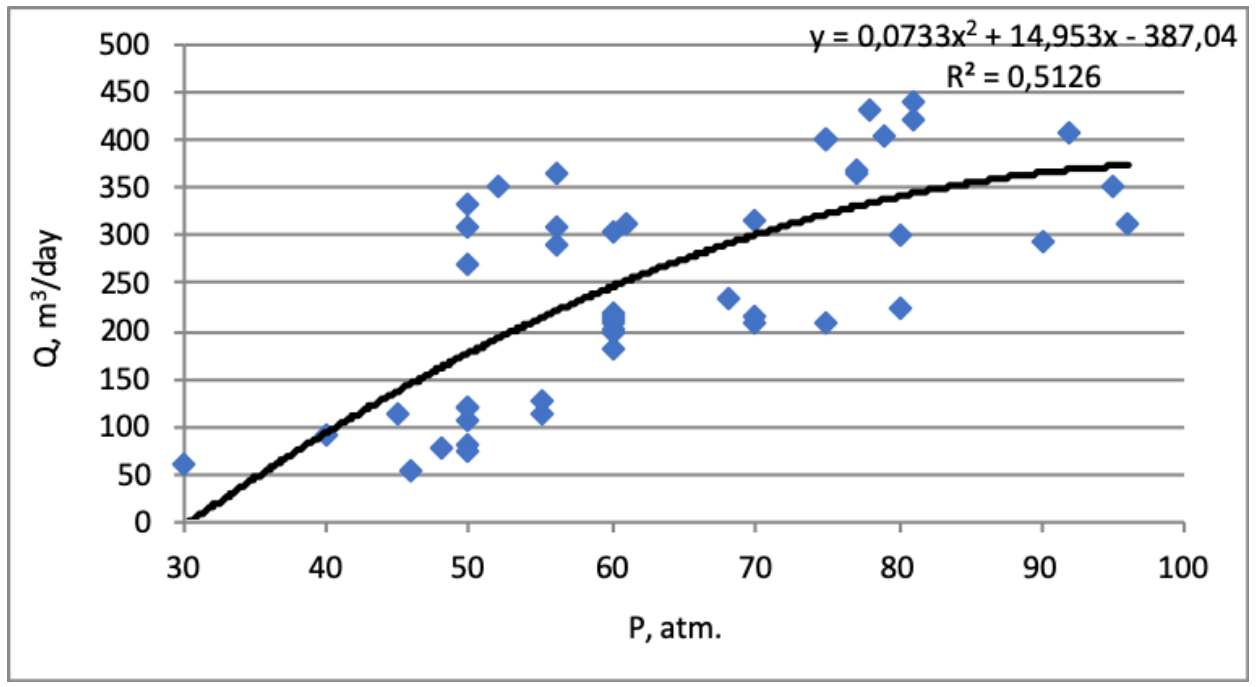

Fig. 4. Example of statistic dependency $Q=f(P)$ for injection well 9972 without BCF. 
Table 1. Filtration properties of injection wells before and after hydraulic fracturing.

\begin{tabular}{|c|c|c|c|c|c|c|c|c|c|c|}
\hline \multirow{3}{*}{$\begin{array}{l}\mathrm{N} \\
\mathrm{o}\end{array}$} & \multirow{3}{*}{$\begin{array}{l}\text { Wellnu } \\
\text { mber }\end{array}$} & \multirow{3}{*}{$\begin{array}{l}\text { Fracturin } \\
\text { gdate }\end{array}$} & \multicolumn{7}{|c|}{ Differenceinvalues } & \multirow[t]{3}{*}{$\mathrm{BCF}$ presence } \\
\hline & & & \multirow{2}{*}{$\begin{array}{c}\mathrm{Q}, \\
\mathrm{m}^{3} / \mathrm{da} \\
\mathrm{y}\end{array}$} & \multirow[t]{2}{*}{$\begin{array}{l}\mathrm{P}_{\mathrm{wh}}, \\
\mathrm{atm}\end{array}$} & \multirow[t]{2}{*}{$\begin{array}{l}\mathrm{d}_{\text {chok }} \\
\mathrm{e} \mathrm{mm}\end{array}$} & \multirow{2}{*}{$\begin{array}{c}\mathrm{K}_{\text {injectivity }} \\
\text { tons/day·at } \\
\mathrm{m}\end{array}$} & \multirow[t]{2}{*}{$\begin{array}{l}\text { Skinfa } \\
\text { ctor }\end{array}$} & \multicolumn{2}{|c|}{$\begin{array}{c}\text { Permeability } \\
\cdot 10^{-3} \mathrm{mcm}^{2}\end{array}$} & \\
\hline & & & & & & & & І уч & II уч & \\
\hline 1 & 2998 & $\begin{array}{c}26.05 .201 \\
3\end{array}$ & 164 & 15 & - & 1.5 & 2.68 & 0.279 & -3.156 & \\
\hline 2 & 9921 & $\begin{array}{c}23.02 .201 \\
3\end{array}$ & 148 & - & - & 0.879 & 5.38 & 11.409 & 4.505 & $\begin{array}{c}\text { BCF } \\
\text { aboveshale. } \\
1810.7 \mathrm{~m}\end{array}$ \\
\hline 3 & 9972 & $\begin{array}{c}12.01 .201 \\
4\end{array}$ & 76 & - & -3 & 0.903 & -2.15 & 0.591 & $\begin{array}{c}97.68 \\
5\end{array}$ & \\
\hline 4 & 13621 & $\begin{array}{c}29.04 .201 \\
3\end{array}$ & 40 & -15 & - & 0.63 & 1.76 & 0 & 1.585 & \\
\hline 5 & $\begin{array}{c}19104 \\
3\end{array}$ & $\begin{array}{c}12.05 .201 \\
4\end{array}$ & 21 & -5 & - & 0.306 & -4.52 & 2.285 & 0.663 & \\
\hline 6 & 24802 & $\begin{array}{c}23.04 .201 \\
4\end{array}$ & 89 & - & - & 0.804 & - & 8.183 & 6.289 & $\begin{array}{c}\text { BCF } \\
\text { aboveshale. } \\
1846 \mathrm{~m}\end{array}$ \\
\hline 7 & 24855 & $\begin{array}{c}28.03 .201 \\
4\end{array}$ & 39 & 60 & - & 0.173 & 1 & 1.836 & 1.729 & \\
\hline 8 & 24883 & $\begin{array}{c}30.04 .201 \\
4\end{array}$ & 24 & 5 & - & 0.214 & -3.05 & 3.157 & 0.623 & \\
\hline 9 & 24891 & $\begin{array}{c}11.01 .201 \\
4\end{array}$ & 61 & - & - & 0.081 & 2.14 & 0.994 & 0.606 & \\
\hline 10 & 28643 & $\begin{array}{c}24.02 .201 \\
3\end{array}$ & 17 & 0 & - & 0.206 & 0.52 & 0 & 2.465 & \\
\hline 11 & 28664 & $\begin{array}{c}17.09 .201 \\
3\end{array}$ & 15 & 15 & - & 0.519 & 1.67 & 12.228 & 8.839 & \\
\hline 12 & 9868 & $\begin{array}{c}26.08 .201 \\
3\end{array}$ & 7 & -2 & - & 0.199 & 1.37 & 2.409 & 0.865 & \\
\hline 13 & 9778 & $\begin{array}{c}18.06 .201 \\
4 \\
\end{array}$ & 0 & 0 & - & 0.277 & 3.49 & 0 & 0.142 & \\
\hline
\end{tabular}

At the same time, the dynamics of the same dependencies in the injection well 24802, where near zone permeability was greater than its previous value (before fracking), showed that it tends to unlimited growth (Fig. 5). 


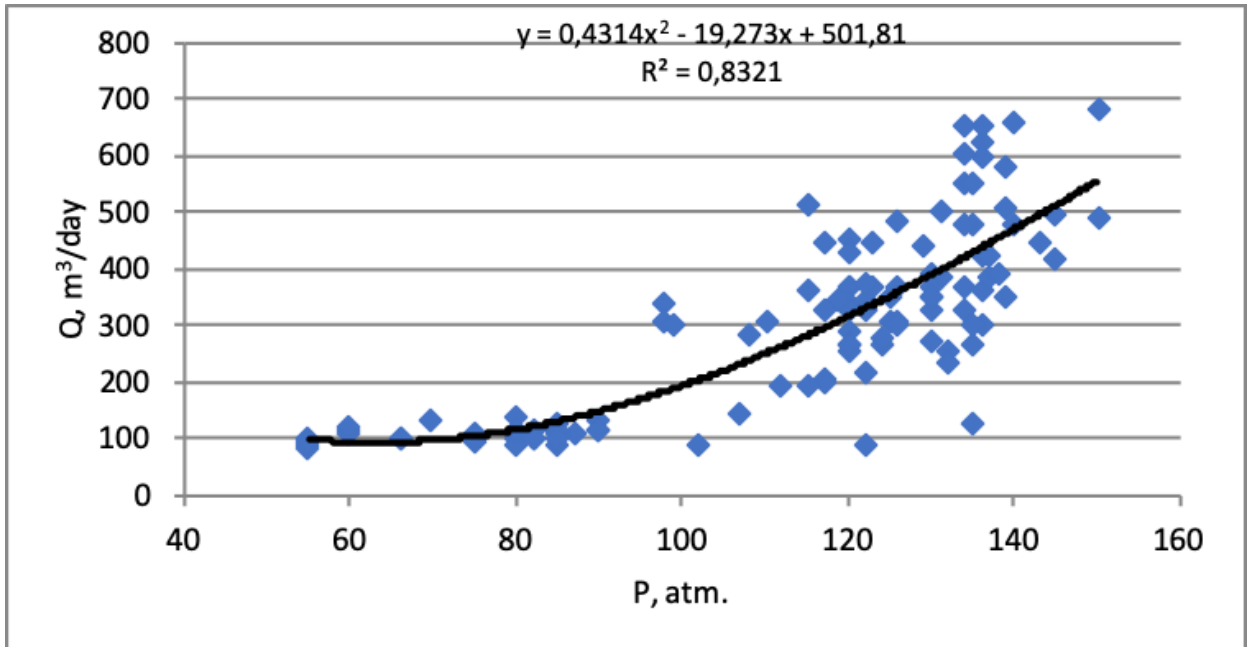

Fig. 5. Example of statistic dependency $Q=f(P)$ for injection well 24802 with $B C F$.

Assessment of WST efficiency in well 24802 using the Mineyev method showed that this led to decrease of injectivity in this well from 85 to $20 \mathrm{~m}^{3} /$ day (Fig. 6, a, b), which confirms the reliability of the conclusion about the presence of BCF.

The result obtained for the detection and elimination of BCF in well 24802 is a confirmation of the Mineyev method for detecting BCF in injection wells and its successful elimination, which allows to reduce the cost of these works by reducing the cost of geophysical well logging and round trip in difficult geological conditions when there is no drill sump for logging or devices cannot pass to the bottom for one reason or another.
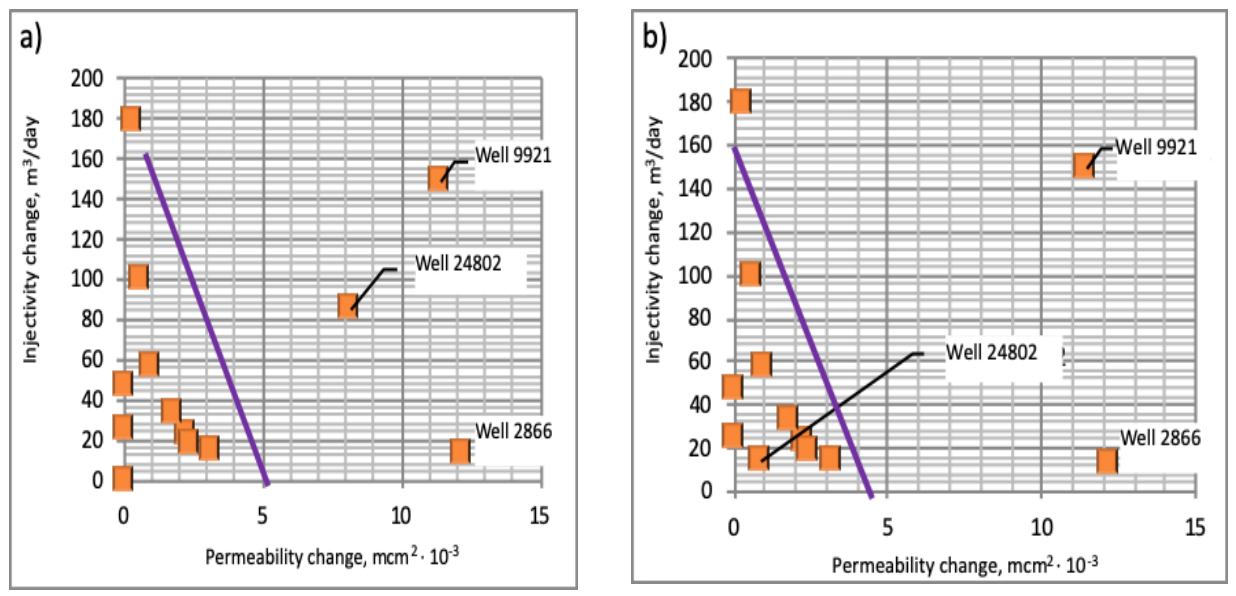

Fig. 6. Correlation and statistical dependence of injectivity on permeability change in near-zone after hydraulic fracturing the injection well 24802: a) before WST; b) after WST.

Figure 6 shows that the technological success of hydraulic fracturing is an increase in the intake capacity of the injection well due to an increase in the permeability of the far zone (area II). An increase in the near zone (area I) indicates the appearance of an additional filtration channel in the deformed part of the cement sheath. Figure $6 \mathrm{~b}$ shows the validity of the above conclusion. For example, after WST works at well 24802, the 
injectivity was $22 \mathrm{~m}^{3} /$ day, and the permeability of the near zone decreased from 8.18 to $1.87 \cdot 10-3 \mathrm{mcm}^{2}$ (Table 1$)$.

\section{RESULTS}

The following regularity has been revealed: an increase in the injectivity (intake capacity) of injection wells is efficient if it is accompanied by a positive change in the permeability of the remote zone and a negative change in the near zone. Otherwise, the injection is inefficient. And those wells that fall out of this pattern can be classified as problematic.

Analyzing the presented in Figures 4 and 5 correlation and statistical dependences of the injection wells $\left.(\mathrm{Q}=\mathrm{f}(\mathrm{P}))^{\circ} \mathrm{C}\right)$, it is possible to identify the presence of two main behaviors of curves (line 2 and line 3 ) and present them as indicator lines which can be used in the diagnostic evaluation of hydraulic fracturing efficiency in the flooding pattern for determining the presence of inefficient injection because of the BCF (Fig. 7). At the same time, line 1 characterizes the ideal case of filtration into an ordinary tube on surface conditions.

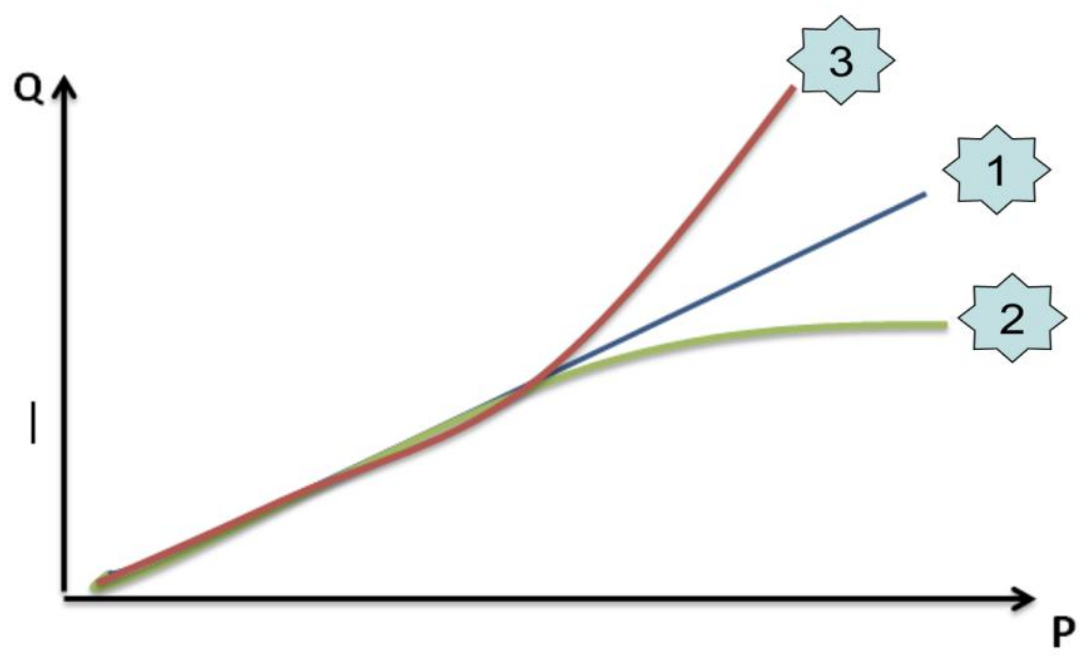

Fig. 7. Indicating lines that describe correlation and statistical dependences $Q=f(P) \cdot C$.

Since the elimination of BCF is a complex-type repair, the success and effectiveness of which is rarely achieved by existing technologies, the authors suggest a reliable and effective way to isolate BCF zones in order to increase the efficiency of WST. The essence of this method is as follows: first, in the BCF interval determined by logging the section 10 is cut out (Fig.8) from casing 6, after which the following layout is run into the well: swelling packer 1 , undocking node 2 , nipple 7 , tubing 3 with packer 4 . Swellable packer 1 should be installed directly opposite the cut-out section of casing 10 . With the lowered layout, viscoelastic compositions are injected to create the initial hydraulic resistance of both formation 11 and the annular space. Then the well is connected (the scheme is not shown in Fig. 8), brought into production, and operated in a normal regime. 


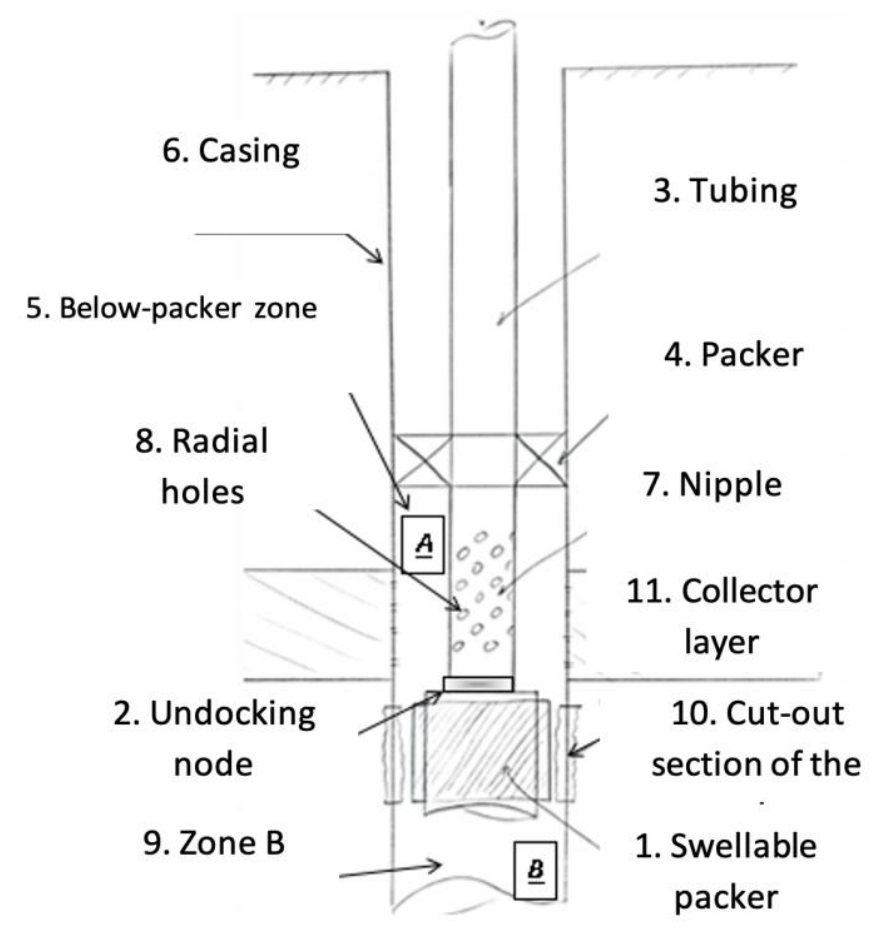

Fig. 8. The proposed layout scheme of downhole pumping equipment for the BCF elimination $[6,7$, $8,9]$.

During the well operation, geophysical logging is performed to determine the connection of below-packer zone 5 (zone A) with zone B (to check the tightness of swelling packer 1). If necessary, after the swelling of packer 1 , it is possible to perform production maintenance with the lifting subsurface equipment, undocking it below nipple 7 from docking node 2 .

The swelling element of packer 1 is quite tightly in contact with the rock in the interval of cut section 10 , so the elimination of $\mathrm{BCF}$, in this case, will be fully provided.

\section{CONCLUSIONS}

Based on the research results, the following conclusions were made:

1. For justification of the need for BCF elimination workover, it is necessary to analyze the results of well testing and correlation and statistical dependencies of the function $\mathrm{Q}=\mathrm{f}(\mathrm{P}) * \mathrm{C}$

2. For the successful performance of BCF workover, it is advisable to use layouts with swellable packers.

\section{REFERENCES}

1. N.M.Anisur Rahman, S.A.Bin Akresh. F.M.Al-Thawad. Diagnosis and characterization of cross-flow behind casing from transient pressure tests. SPE Annual Technical Conference and Exhibition, 28-30 September, Texas, USA.(2015). 
2. S. Perrier, Detection of cross-flwos behind casing before perforations, and cement isolation diagnosis based on temperature analysis (TUNU field, Indonesia). International Petroleum Technology Conference, European Association of Geoscientists and Engineers(2012).

3. T.Eltsov, T.W. Patzek, Beyond steel casing: detecting zonal isolation in the borehole environment. SPE Middle East Oil and Gas Show and Conference,(2019)

4. B.I. Kirpichenko, Possibility of determining the movement of liquid in the annular space by acoustic method. Oil industry,4: 21-23(1973).

5. Instructions for processing the results of well tests. (JSC Tatneft. Almetyevsk, 1998).

6. Patent. 2549639 Russian Federation, MPE E 21 B 43/20. Method of developing oil fields. Y.A. Gutorov, L.G. Rakhmaev Applicant and patent holder Gutorov Y.A. No. 2013151579; appl. 19.11.13; publ. 27.04.15, bulletin 12 .

7. Patent. 2713279 Russian Federation, SEC E 21 B 3312. Method of behind-the-casing flow isolation in wells. L.G. Rakhmaev. The applicant and patent holder PAO Tatneft named after V.D. Shashin. - No. 2019108701; appl 26.03.2019; publ. 04.02.2020, bulletin 4 .

8. L.G.Rakhmaev, Y.A. Gutorov, Research and control of filtration flow directions during local flooding of the Pashian horizon. Modern technologies in oil and gas business2013: a collection of scientific papers. International. Scientific technical conference. USPTU,1: 308-317(2011).

9. L.G. Rakhmaev, Research and control of behind-the-casing flow elimination. Collection of abstracts of the young specialists' seminar, section "Geology, development of oil and gas fields": 67-72 (2015). 